\title{
Synthesis, Antioxidant, Xanthine Oxidase and Urease Inhibitory Activities of Some Chlorine Containing Benzimidazoles
}

\section{Bazı Klor İçeren Benzimidazollerin Sentezi ve Antioksidan, Ksantin Oksidaz ve Üreaz İnhibitör Aktivitelerinin İncelenmesi}

\author{
Research Article
}

Nimet Baltaş*, Fatih Yılmaz, Emre Menteşe

Department of Chemistry, Art and Science Faculty, Recep Tayyip Erdogan University, Rize, Turkey.

\section{A B S TR ACT}

\begin{abstract}
series of tetra-substitued benzimidazole derivatives were synthesized and screened for their urease inhibition, anti-xanthine oxidase (XO) and antioxidant activities. Some of them were found to possess significant antioxidant activity, especially, compounds $4,5 a, 5 b, 5 c, 5 d$ and $6 b$ exhibited highly scavenging activity in ABTS + radical cation decolorization assay $\left(\mathrm{SC}_{50}: 9.51-70.43 \mu \mathrm{g} / \mathrm{mL}\right)$ and cupric reducing antioxidant capacity (CUPRAC) assay. Compound $6 \mathrm{~d}$ exhibited the highest XO inhibition at $125 \mu \mathrm{g} / \mathrm{mL}$. All compounds were evaluated with regard to Jack Bean urease activity and the most active compound concerning urease enzyme inhibition was (5b), with an $I C_{50}$ value of $7.41 \pm 0.13 \mu \mathrm{g} / \mathrm{mL}$.
\end{abstract}

\section{Key Words}

Urease, xanthine oxidase, enzyme inhibition, antioxidant activity, benzimidazole.

\section{ÖZET}

ir seri tetra-substitüe benzimidazol türevi sentezlendi ve üreaz inhibisyon, anti-ksantin oksidaz (XO) ve antioksidan aktiviteleri incelendi. Bazı bileşiklerin önemli derecede antioksidan aktivite gösterdiği tespit edildi. Özellikle, bileşik 4,5a, 5b, 5c, $5 \mathrm{~d}$ ve $6 \mathrm{~b}$ ABTS•+ radikal katyon temizleme $\left(\mathrm{SC}_{50}: 9.51-70.43 \mu \mathrm{g} / \mathrm{mL}\right) \mathrm{ve}$ bakır indirgeyici antioksidan kapasite (CUPRAC) tayininde yüksek derecede aktivite gösterdiği belirlendi. Bileşik $6 \mathrm{~d}$ ise, $125 \mu \mathrm{g} / \mathrm{mL}$ derişimde en yüksek anti-ksantin oksidaz (XO) aktivitesi gösterdi. Bütün bileşikler Jack Bean üreaz aktivite tayin yöntemine göre incelendi ve en aktif üreaz inhibisyonuna sahip bileşiğin $7.41 \pm 0.13 \mu \mathrm{g} / \mathrm{mL}$ $I_{50}$ değeriyle (5b) olduğu tespit edildi.

\section{Anahtar Kelimeler}

Üreaz, ksantin oksidaz, enzim inhibisyon, antioksidan aktivite, benzimidazol.

Article History: Received: Jan 28, 2016; Revised: Jun 14, 2016; Accepted: Jun 20, 2016; Available Online: Jul $31,2016$. DOI: 10.15671/HJBC.20164420572

Correspondence to: N. Baltaş, Recep Tayyip Erdogan University, Faculty of Arts and Sciences, Department of Chemistry, Rize, Turkey. 


\section{INTRODUCTION}

U rease (EC 3.5.1.5) is a nickel containing enzyme that catalyzes the hydrolysis of urea to the formation of ammonia and carbon dioxide, which is the final step of nitrogen metabolism in living organisms $[1,2]$. Ureases producing excess ammonium are also involved in the development of urolithiasis, pyelonephritis, hepatic encephalopathy, hepatic coma urolithiasis, and urinary catheter encrustation in humans and animals $[3,4]$. The urease activity of Helicobacter pylori plays an important role in the pathogenesis of gastric and peptic ulcer [3]. The requirement to treat such infections has stimulated intensive studies on various groups of urease inhibitors. Hydroxamic acids, phosphoramidates [5] hydroxamic acid derivatives [6], polyphenols [7], 1,2,4-triazoles [8], 1,4-Disubstituted Thiosemicarbazides [9], 7-aminocephalosporanic acid derivatives [10], 1,3,4-oxadiazoles and 1,3,4-thiadiazoles [5], hydroxyurea [11] phosphorodiamidates [12], imidazoles such as rabeprazole [13], lansoprazole [14], omeprazole [15], quinines [16], thiol-compounds [17], and plaunotol and its thiourea derivatives have been reported as the compounds possessing antiurease activity. So, urease inhibitors have the potential to be used as anti-ulcer drugs.

Xanthine oxidase (XO) is a key enzyme catalysing the oxidation of oxypurines (hypoxanthine and xanthine) to uric acid in the purine metabolic pathway [18]. Elevated concentrations of uric acid in the blood stream of human body leads to formation of gout, characterized by hyperuricemia and recurrentattacks of arthritis [19]. Allopurinol is the only clinically used $\mathrm{XO}$ inhibitor (XOI), approved by the Food and Drug Administration in 1966, which also suffers from many side effects such as, hypersensitivity syndrome, liver function abnormalities [20], Stevens-Johnson syndrome, a fatal complication known as "allopurinol hypersensitivity syndrome" [21,22], renal toxicity due to impairment of pyrimidine metabolism. On the other hand, allopurinol generates superoxide23 and some people develop rash as they are allergic to allopurinol [21,24]. XO also serves as an important biological source of oxygen derived free radicals that contribute to oxidative damage to living tissues involved in many pathological processe such as inflammation, atherosclerosis, cancer and aging [25].

Reactive oxygen species (ROS) in the form of superoxide anion $\left(\cdot \mathrm{O}_{2}{ }^{-}\right)$, hydroxyl radical $(\mathrm{HO} \cdot)$ and hydrogen peroxide $\left(\mathrm{H}_{2} \mathrm{O}_{2}\right)$ attack various biological macromolecules (proteins, enzymes, DNA, etc.) under 'oxidative stress' conditions, give rise to a number of inflammatory, metabolic disorders, cellular aging, reperfusion damage and cancer [26]. Antioxidant compounds delay or prevent the oxidation of cellular oxidizable substrates by direct radical scavenging action or indirect antioxidant action, such as the inhibition of ROS-producing enzymes ( $\mathrm{XO}$, lipoxygenase, etc.) [27]. Hence, agents with the ability to protect against these reactive species may be therapeutically useful.

The five-membered nitrogen containing heterocyclic compounds continue to play an important role in medicinal chemistry [28]. Each year, a large number of drug candidates which contain heterocyclic ring are synthesized by researchers [29]. Among these types of compounds benzimidazole derivatives which are present in a wide variety of medicine such as albendazole, thiabendazole, omeprazole, carbendazim, mebendazole, timoprazole, and found naturally in the structure of vitamin B12 [30,31]. Different heterocyclic rings (like 1,2,4-triazole, 1,3,4-thiadiazole and oxadiazole) linked to benzimidazoles have been designated as an important pharmacophores and are well known for their diverse biological activities such as antibacterial, antiinflammatory, antiulcer, antioxidant, antitumor, lipase inhibition, glutaminyl cyclase inhibition, anti-enterovirus and anticancer activities [32-37]. Literature survey reveals that benzimidazole derivatives indicated appreciable antimycobacterial activity [38-41]. Besides, benzimidazoles bearing thiosemicarbazide and triazole ring demonstrated appreciable antioxidant activity $[42,43]$. Also, it has been found that insertion of chlorine, in the structures of heterocyclic compounds leads to an increase of biological activity [44]. 
Studies on enzyme inhibition remain an important area of pharmaceutical research since these studies have led to the discoveries of useful drugs in a variety of physiological conditions. In the current paper, we present the synthesis of clorine containing benzimidazole derivatives containing 1,2,4-triazole and 1,3,4-thiadiazole ring with their evaluation antioxidant properties, inhibitory activity against Jack bean urease and bovine milk xanthine oxidase. In vitro bioassays are used to investigate test material for $\mathrm{XO}$ inhibition, as inhibitors of XO may be potentially beneficial for the treatment of gout or other $x O$ caused diseases.

\section{EXPERIMENTAL}

\section{Chemistry}

All the chemicals were supplied by Merck (Darmstadt, Germany), Aldrich and Fluka (Buchs SG, Switzerland). Melting points were determined on capillary tubes on a Büchi oil-heated melting point apparatus (Essen, Germany) and are uncorrected. ${ }^{1} \mathrm{H}-\mathrm{NMR}$ and ${ }^{13} \mathrm{C}$-NMR spectra were performed on the Varian-Mercury $400 \mathrm{MHz}$ spectrometer (Varian, Darmstadt, Germany) in DMSO-d $d_{6}$ using TMS as internal standard. Elemental analyses were performed on a Carla Erba 1106 CHN analyser (Heraeus, Hanau, Germany). All reactions were monitored by TLC using precoated aluminum sheets (silica gel $60 \mathrm{~F}$ $2.540 .2 \mathrm{~mm}$ thickness).

\section{Synthesis of Methyl [5, 6-dichloro-2-(3,4- dichlorobenzyl)-1 $\mathrm{H}$-benzimidazol-1-yl]acetate} (3)

Compound $2(0.01 \mathrm{~mol})$ and dry $\mathrm{K}_{2} \mathrm{CO}_{3}(0.025$ $\mathrm{mol})$ in acetone $(30 \mathrm{~mL})$ were taken in a round bottomed flask and the mixture was stirred for 10 min. Then, methyl bromoacetate $(0.011 \mathrm{~mol})$ was added to the mixture and the mixture was stirred for 10 hours. After the reaction was completed (controlled by TLC, ethyl acetate/hexane, 3/1), water was added to the mixture to precipitate the product. Then, it was filtrated off, dried and recrystallized from ethanol.

Yield: $3.80 \mathrm{~g}$ (91\%); Mp: $147-148^{\circ} \mathrm{C} ;{ }^{1} \mathrm{H}-\mathrm{NMR}$ (400 MHz, DMSO-d $\left.\mathrm{d}_{6}\right) \delta(\mathrm{ppm}): 3.56\left(\mathrm{~s}, 3 \mathrm{H}_{1} \mathrm{OCH}_{3}\right)$, $4.29\left(\mathrm{~s}, 2 \mathrm{H}, \mathrm{CH}_{2}\right), 5.28\left(\mathrm{~s}, 2 \mathrm{H}, \mathrm{NCH}_{2}\right), 7.26(\mathrm{dd}$
$\left.J=8.0, J=2.0,{ }^{1} \mathrm{H}, \operatorname{Ar}-\mathrm{H}\right), 7.55(\mathrm{~m}, 2 \mathrm{H}, \mathrm{Ar}-\mathrm{H}), 7.88$ (s, $\left.{ }^{1} \mathrm{H}, \mathrm{Ar}-\mathrm{H}\right), 7.95\left(\mathrm{~s},{ }^{1} \mathrm{H}, \mathrm{Ar}-\mathrm{H}\right){ }^{13} \mathrm{C}-N M R(100 \mathrm{MHz}$, DMSO- $\left.\mathrm{d}_{6}\right): \delta 32.06\left(\mathrm{CH}_{2}\right), 45.12\left(\mathrm{NCH}_{2}\right), 52.78$ $\left(\mathrm{OCH}_{3}\right), 112.73,120.37,124.91,125.29,129.93$, 130.04, 130.99, 132.33, 131.52, 135.72, 137.49, $142.00(\mathrm{Ar}-\mathrm{C}), 156.30(\mathrm{C}=\mathrm{N}), 168.43(\mathrm{C}=\mathrm{O})$. Anal. Calcd. for $\mathrm{C}_{17} \mathrm{H}_{12} \mathrm{Cl}_{4} \mathrm{~N}_{2} \mathrm{O}_{2}: \mathrm{C}, 48.84 ; \mathrm{H}, 2.89 ; \mathrm{N}$, $6.70 \%$. Found: $\mathrm{C}, 48.80 ; \mathrm{H}, 2.86 ; \mathrm{N}, 6.67 \%$.

\section{Synthesis of 2-[5, 6-dichloro-2-(3,4- dichlorobenzyl)-1 $\mathrm{H}$-benzimidazol-1-yl] acetohydrazide (4)}

A mixture of compound $3(0.01 \mathrm{~mol})$ in ethanol (25 $\mathrm{mL}$ ) was taken in a round-bottomed flasked and hydrazine monohydrate $(0.025 \mathrm{~mol})$ was added. Then, the mixture was refluxed for 6 hours. After the reaction was completed (controlled by TLC, ethyl acetate/hexane, 3/1), the mixture was left to cool to room temperature. Then, a white solid was appeared. This crude product was filtrated off, dried and recrystallized from ethanol.

Yield: $3.05 \mathrm{~g}$ (73\%); Mp: $227-228^{\circ} \mathrm{C} ;{ }^{1} \mathrm{H}-\mathrm{NMR}$ (400 MHz, DMSO-d $)_{6} \delta$ (ppm): $4.19\left(\mathrm{~s}, 2 \mathrm{H}, \mathrm{CH}_{2}\right)$, $4.57\left(\mathrm{~s}, 2 \mathrm{H}, \mathrm{NH}_{2}\right), 5.27\left(\mathrm{~s}, 2 \mathrm{H}, \mathrm{NCH}_{2}\right), 7.30(\mathrm{~d}$, $\left.J=8.0,{ }^{1} \mathrm{H}, \operatorname{Ar}-\mathrm{H}\right), 7.60(\mathrm{~m}, 2 \mathrm{H}, \operatorname{Ar}-\mathrm{H}), 7.79\left(\mathrm{~s},{ }^{1} \mathrm{H}\right.$, Ar-H), $7.84\left(\mathrm{~s},{ }^{1} \mathrm{H}, \mathrm{Ar}-\mathrm{H}\right), 9.52\left(\mathrm{~s},{ }^{1} \mathrm{H}, \mathrm{NH}\right) ;{ }^{13} \mathrm{C}-\mathrm{NMR}$ $\left(100 \mathrm{MHz}\right.$, DMSO- $\left.\mathrm{d}_{6}\right): \delta 32.18\left(\mathrm{CH}_{2}\right), 45.24\left(\mathrm{NCH}_{2}\right)$, $112.47,120.15,124.40,124.78,129.87,130.14$, 130.92, 131.46, 135.66, 136.08, 138.01, 142.11 (ArC), $156.90(C=N), 165.95(C=0)$. Anal. Calcd. for $\mathrm{C}_{16} \mathrm{H}_{12} \mathrm{Cl}_{4} \mathrm{~N}_{4} \mathrm{O}: \mathrm{C}, 45.96 ; \mathrm{H}, 2.89 ; \mathrm{N}, 13.40 \%$. Found: C, 45.93; H, 2.85; N, 13.35\%.

\section{Synthesis of Compound $5 \mathrm{a}-\mathrm{d}$}

A mixture of compound $4(0.01 \mathrm{~mol})$ and corresponding isothiocyanate derivative (0.01 mol) in ethanol ( $25 \mathrm{~mL}$ ) was refluxed for $2 \mathrm{~min}$. After the reaction was completed (controlled by TLC, ethyl acetate/hexane, 4/1), the mixture was left to cool to room temperature and the crude product was observed by addition of water. It was filtrated off and recrystallized from ethyl acetate to afford the desired product.

2-\{[5,6-Dichloro-2-(3,4-dichlorobenzyl)${ }^{1} \mathrm{H}-\mathrm{b}$ e n zimida $\mathrm{zol}-1-\mathrm{yl}$ ] a c e ty I \} - N methylhydrazinecarbothioamide (5a). Yield: $3.78 \mathrm{~g}(77 \%) ; \mathrm{Mp}: 235-236^{\circ} \mathrm{C} ;{ }^{1} \mathrm{H}-\mathrm{NMR}(400 \mathrm{MHz}$, DMSO- $\left._{6}\right) \delta(\mathrm{ppm}): 2.91\left(\mathrm{~s}, 3 \mathrm{H}, \mathrm{CH}_{3}\right), 4.27(\mathrm{~s}, 2 \mathrm{H}$, 
$\left.\mathrm{CH}_{2}\right), 5.02\left(\mathrm{~s}, 2 \mathrm{H}, \mathrm{CH}_{2}\right), 7.30\left(\mathrm{~m},{ }^{1} \mathrm{H}, \mathrm{Ar}-\mathrm{H}\right), 7.58$ $(\mathrm{m}, 2 \mathrm{H}, \mathrm{Ar}-\mathrm{H}), 7.87(\mathrm{~m}, 2 \mathrm{H}, \mathrm{Ar}-\mathrm{H}), 8.62\left(\mathrm{~s},{ }^{1} \mathrm{H}, \mathrm{NH}\right)$ $9.43\left(\mathrm{~s},{ }^{1} \mathrm{H}, \mathrm{NH}\right), 10.25\left(\mathrm{~s},{ }^{1} \mathrm{H}, \mathrm{NH}\right) ;{ }^{13} \mathrm{C}-\mathrm{NMR}(100$ $\left.\mathrm{MHz}, \mathrm{DMSO}-\mathrm{d}_{6}\right): \delta 31.39\left(\mathrm{CH}_{3}\right), 32.02\left(\mathrm{CH}_{2}\right), 45.23$ $\left(\mathrm{NCH}_{2}\right), 112.65,120.35,124.72,125.01,129.90$, $130.15,131.35,131.54,131.67,135.82,137.92,142.18$ $(\operatorname{Ar}-\mathrm{C}), 156.87(C=N), 166.59(C=0), 170.40(C=S)$. Anal. Calcd. for $\mathrm{C}_{18} \mathrm{H}_{15} \mathrm{Cl}_{4} \mathrm{~N}_{4} \mathrm{OS}$ : C, 44.01; $\mathrm{H}, 3.08 ; \mathrm{N}$ $14.26 \%$. Found: $C, 43.94 ; H, 3.03 ; N, 14.21 \%$.

\section{2- $\{[5,6$-Dichloro-2-(3,4-dichlorobenzyl)-} ${ }^{1} \mathrm{H}-\mathrm{b}$ e n zimidazol-1-yl] a c e t y I $-\mathrm{N}$ ethylhydrazinecarbothioamide (5b). Yield:3.74 g (74\%); Mp: $215-216^{\circ} \mathrm{C}$; ${ }^{1} \mathrm{H}-\mathrm{NMR}$ (400 MHz, DMSO- $\left.\mathrm{d}_{6}\right) \delta(\mathrm{ppm}): 1.08\left(\mathrm{t}, \mathrm{J}=6.8,3 \mathrm{H}_{1} \mathrm{CH}_{3}\right), 3.48$ (q, J=6.8,2 $\left.\mathrm{H}_{2} \mathrm{CH}_{2}\right), 4.27\left(\mathrm{~s}, 2 \mathrm{H}, \mathrm{CH}_{2}\right), 5.37(\mathrm{~s}, 2 \mathrm{H}$, $\left.\mathrm{NCH}_{2}\right), 7.29(\mathrm{~m}, 1 \mathrm{H}, \mathrm{Ar}-\mathrm{H}), 7.53(\mathrm{~s}, 2 \mathrm{H}, \mathrm{Ar}-\mathrm{H}), 7.86$ (s, 2H, Ar-H), $8.12\left(\mathrm{~s},{ }^{1} \mathrm{H}, \mathrm{NH}\right), 9.27\left(\mathrm{~s},{ }^{1} \mathrm{H}, \mathrm{NH}\right), 10.27$ $\left(\mathrm{s},{ }^{1} \mathrm{H}, \mathrm{NH}\right) ;{ }^{13} \mathrm{C}-\mathrm{NMR}\left(100 \mathrm{MHz}, \mathrm{DMSO}-\mathrm{d}_{6}\right): \delta 14.80$ $\left(\mathrm{CH}_{3}\right), 32.02\left(\mathrm{CH}_{2}\right), 37.78\left(\mathrm{CH}_{2}\right), 45.23\left(\mathrm{NCH}_{2}\right)$, $112.68,120.29,124.72,125.11,130.03,130.91$, $131.35,131.66,135.80,137.93,142.18(\mathrm{Ar}-\mathrm{C}), 156.72$ $(C=N), 166.48(C=0), 170.39(C=S)$. Anal. Calcd. for $\mathrm{C}_{19} \mathrm{H}_{17} \mathrm{Cl}_{4} \mathrm{~N}_{4} \mathrm{OS}: \mathrm{C}, 45.17 ; \mathrm{H}, 3.39 ; \mathrm{N}, 14.86 \%$. Found: C, 45.12; H, 3.31; N, 14.82\%.

2-\{[5,6-Dichloro-2-(3,4-dichlorobenzyl)${ }^{1} \mathrm{H}-\mathrm{b}$ e n zi midazol-1-yl] a c e ty I \} - N phenylhydrazinecarbothioamide (5c). Yield:3.76 g (0.68\%); Mp: $214-215^{\circ} \mathrm{C}$; ${ }^{1} \mathrm{H}-\mathrm{NMR}$ (400 MHz, DMSO- $\left.\mathrm{d}_{6}\right) \delta(\mathrm{ppm}): 4.31\left(\mathrm{~s}, 2 \mathrm{H}, \mathrm{CH}_{2}\right), 5.12(\mathrm{~s}, 2 \mathrm{H}$, $\left.\mathrm{NCH}_{2}\right), 7.19-7.61(\mathrm{~m}, 10 \mathrm{H}, \operatorname{Ar}-\mathrm{H}), 7.87\left(\mathrm{~s},{ }^{1} \mathrm{H}, \mathrm{NH}\right)$ $9.93\left(\mathrm{~s},{ }^{1} \mathrm{H}, \mathrm{NH}\right), 10.42\left(\mathrm{~s},{ }^{1} \mathrm{H}, \mathrm{NH}\right) ;{ }^{13} \mathrm{C}-\mathrm{NMR}(100$ $\mathrm{MHz}$, DMSO-d $\left.\mathrm{d}_{6}\right): \delta 32.11\left(\mathrm{CH}_{2}\right), 45.31\left(\mathrm{NCH}_{2}\right), 112.72$, $117.49,120.59,125.15,125.92,129.44,129.95$, $130.07,130.15,130.97,131.49,131.57,135.70,137.95$, 139.37, $142.16(\operatorname{Ar}-\mathrm{C}), 156.75(C=N), 160.64(C=0)$, $166.64(\mathrm{C}=\mathrm{S})$. Anal. Calcd. for $\mathrm{C}_{23} \mathrm{H}_{17} \mathrm{Cl}_{4} \mathrm{~N}_{4} \mathrm{OS}$ : C, 49.93; $H, 3.10 ; N, 12.66 \%$. Found: $C, 49.86 ; H_{1}$ $3.05 ; \mathrm{N}, 12.62 \%$.

2- $\left\{\left[5,6\right.\right.$-Dichloro-2-(3,4-dichlorobenzyl)- ${ }^{-1} \mathrm{H}^{-}$ benzimidazol-1-yl]acetyl\}-N-(4-bromophenyl) hydrazinecarbothioamide (5d). Yield:4.04 g (64\%); Mp: $204-205^{\circ} \mathrm{C}$; ${ }^{1} \mathrm{H}-\mathrm{NMR}$ (400 MHz, DMSO- $\left.\mathrm{d}_{6}\right) \delta(\mathrm{ppm}): 4.30\left(\mathrm{~s}, 2 \mathrm{H}, \mathrm{CH}_{2}\right), 5.08(\mathrm{~s}, 2 \mathrm{H}$, $\left.\mathrm{NCH}_{2}\right), 7.22-7.58(\mathrm{~m}, 9 \mathrm{H}, \mathrm{Ar}-\mathrm{H}), 7.92\left(\mathrm{~s},{ }^{1} \mathrm{H}, \mathrm{NH}\right)$, $9.80\left(\mathrm{~s},{ }^{1} \mathrm{H}, \mathrm{NH}\right), 10.51\left(\mathrm{~s},{ }^{1} \mathrm{H}, \mathrm{NH}\right) ;{ }^{13} \mathrm{C}-\mathrm{NMR}(100$ $\left.\mathrm{MHz}, \mathrm{DMSO}-\mathrm{d}_{6}\right): \delta 32.12\left(\mathrm{CH}_{2}\right), 45.29\left(\mathrm{NCH}_{2}\right), 112.73$,
$113.87,119.47,120.57,124.79,125.10,129.88,130.04$, $130.98,131.37,132.19,135.40,135.65,137.25$, 138.81, $142.11(\operatorname{Ar}-\mathrm{C}), 156.88(C=N), 160.31(C=0)$, 166.60 (C=S). Anal. Calcd. for $\mathrm{C}_{23} \mathrm{H}_{16} \mathrm{BrCl}_{4} \mathrm{~N}_{4} \mathrm{OS}: \mathrm{C}$, 43.70; $\mathrm{H}, 2.55 ; \mathrm{N}, 11.08 \%$. Found: $\mathrm{C}, 43.64 ; \mathrm{H}, 2.51$; $\mathrm{N}, 11.02 \%$.

\section{Synthesis of Compound 6a-d}

A solution of corresponding carbothioamide $5 a-d(0.01 \mathrm{~mol})$ in ethanol/water (1:1) $30 \mathrm{~mL}$ was refluxed for 5 hours in the presence of $2 \mathrm{~N} \mathrm{NaOH}$. Then, the resulting solution was cooled to room temperature and acidified to $\mathrm{pH} 3-4$ with $2 \mathrm{~N}$ $\mathrm{HCl}$. The crude product was precipitated. It was filtrated off, washed with water and recrystallized from ethanol/water (1:1) to afford compound 6a-d.

5- $\left\{\left[5,6-\right.\right.$ Dichloro-2-(3,4-dichlorobenzyl) ${ }^{-1} \mathrm{H}-$ benzimidazol-1-yl]methyl\}-4-methyl-4H-1,2,4triazole-3-thiol (6a). Yield:3.45 g (73\%); Mp: 231$233^{\circ} \mathrm{C} ;{ }^{1} \mathrm{H}-\mathrm{NMR}\left(400 \mathrm{MHz}, \mathrm{DMSO}-\mathrm{d}_{6}\right) \delta(\mathrm{ppm}): 3.41$ $\left(\mathrm{s}, 3 \mathrm{H}, \mathrm{CH}_{3}\right), 4.30\left(\mathrm{~s}, 2 \mathrm{H}, \mathrm{CH}_{2}\right), 5.63\left(\mathrm{~s}, 2 \mathrm{H}, \mathrm{NCH}_{2}\right)$, $7.23\left(\mathrm{~d}, J=7.6,{ }^{1} \mathrm{H}, \mathrm{Ar}-\mathrm{H}\right), 7.48-7.65(\mathrm{~m}, 2 \mathrm{H}, \mathrm{Ar}-\mathrm{H})$, $7.89\left(\mathrm{~s},{ }^{1} \mathrm{H}, \mathrm{Ar}-\mathrm{H}\right), 8.01\left(\mathrm{~s},{ }^{1} \mathrm{H}, \mathrm{Ar}-\mathrm{H}\right) ;{ }^{13} \mathrm{C}-\mathrm{NMR}(100$ $\mathrm{MHz}$, DMSO-d $\left.\mathrm{d}_{6}\right): \delta 30.21\left(\mathrm{CH}_{3}\right), 32.06\left(\mathrm{CH}_{2}\right), 40.35$ $\left(\mathrm{NCH}_{2}\right), 112.86,120.32,124.81,125.13,129.88$, 130.05, 130.85, 131.30, 131.59, 135.54, 137.82, $142.16(\operatorname{Ar}-\mathrm{C}), 147.44(\mathrm{C}=\mathrm{N}), 156.59(\mathrm{C}=\mathrm{N}), 168.32$ (C=S). Anal. Calcd. for $\mathrm{C}_{18} \mathrm{H}_{13} \mathrm{Cl}_{4} \mathrm{~N}_{5} \mathrm{~S}: \mathrm{C}$, 45.69; $\mathrm{H}, 2.77 ; \mathrm{N}, 14.80 \%$. Found: $\mathrm{C}, 45.61 ; \mathrm{H}, 2.72 ; \mathrm{N}$, $14.73 \%$.

5-\{[5,6-Dichloro-2-(3,4-dichlorobenzyl)${ }^{1} \mathrm{H}$-benzimidazol-1-yl]methyl\}-4-ethyl-4H-1,2,4triazole-3-thiol (6b). Yield: $3.21 \mathrm{~g}(66 \%) ; \mathrm{Mp}: 253-$ $254^{\circ} \mathrm{C} ; i^{1} \mathrm{H}-\mathrm{NMR}\left(400 \mathrm{MHz}\right.$, DMSO-d $\left.{ }_{6}\right) \delta$ (ppm): 1.23 $\left(\mathrm{t}, J=6.4,3 \mathrm{H}, \mathrm{CH}_{3}\right), 4.03\left(\mathrm{q}, J=6.4,2 \mathrm{H}, \mathrm{CH}_{2}\right), 5.09$ $\left(\mathrm{s}, 2 \mathrm{H}, \mathrm{CH}_{2}\right), 5.75\left(\mathrm{~s}, 2 \mathrm{H}, \mathrm{NCH}_{2}\right), 7.22(\mathrm{~d}, \mathrm{~J}=7.6$, $\left.{ }^{1} \mathrm{H}, \mathrm{Ar}-\mathrm{H}\right), 7.48-7.55\left(\mathrm{~m},{ }^{2} \mathrm{H}, \mathrm{Ar}-\mathrm{H}\right), 7.89\left(\mathrm{~s},{ }^{1} \mathrm{H}, \mathrm{Ar}-\right.$ $\mathrm{H}), 8.01\left(\mathrm{~s},{ }^{1} \mathrm{H}, \mathrm{Ar}-\mathrm{H}\right), 13.51\left(\mathrm{~s},{ }^{1} \mathrm{H}, \mathrm{SH}\right) ;{ }^{13} \mathrm{C}-\mathrm{NMR}$ $\left(100 \mathrm{MHz}, \mathrm{DMSO}-\mathrm{d}_{6}\right): \delta 13.52\left(\mathrm{CH}_{3}\right), 32.07\left(\mathrm{CH}_{2}\right)$, $39.03\left(\mathrm{CH}_{2}\right), 39.34\left(\mathrm{NCH}_{2}\right), 112.66,120.40,124.63$, 125.37, 129.89, 130.05, 130.91, 131.30, 131.40, 135.65, 137.41, 142.07 ( $\operatorname{Ar}-\mathrm{C}), 147.73(\mathrm{C}=\mathrm{N}), 156.38$ $(\mathrm{C}=\mathrm{N}), 167.57(\mathrm{C}=\mathrm{S})$. Anal. Calcd. for $\mathrm{C}_{19} \mathrm{H}_{15} \mathrm{Cl}_{4} \mathrm{~N}_{5} \mathrm{~S}$ : C, 46.84; H, 3.10; N, 14.37\%. Found: $C, 46.80 ; \mathrm{H}$, $3.06 ; \mathrm{N}, 14.32 \%$. 
5-\{[5,6-Dichloro-2-(3,4-dichlorobenzyl)${ }^{1} \mathrm{H}$-benzimidazol-1-yl]methyl\}-4-phenyl-4H-1,2,4triazole-3-thiol (6c). Yield:3.26 g (61\%); Mp: 165$166^{\circ} \mathrm{C} ;{ }^{1} \mathrm{H}-\mathrm{NMR}\left(400 \mathrm{MHz}\right.$, DMSO-d $\left.\mathrm{d}_{6}\right) \delta(\mathrm{ppm}): 4.15$ $\left(\mathrm{s}, 2 \mathrm{H}, \mathrm{CH}_{2}\right), 5.38\left(\mathrm{~s}, 2 \mathrm{H}, \mathrm{NCH}_{z}\right), 7.14-7.58(\mathrm{~m}, 8 \mathrm{H}$, Ar-H), $7.72\left(\mathrm{~s},{ }^{1} \mathrm{H}, \mathrm{Ar}-\mathrm{H}\right), 7.92\left(\mathrm{~s},{ }^{1} \mathrm{H}, \mathrm{Ar}-\mathrm{H}\right){ }^{13}{ }^{13} \mathrm{C}-\mathrm{NMR}$ $\left(100 \mathrm{MHz}, \mathrm{DMSO}-\mathrm{d}_{6}\right): \delta 32.01\left(\mathrm{CH}_{2}\right), 40.58\left(\mathrm{NCH}_{2}\right)$, $112.75,117.50,120.57,124.81,125.51,128.57$, $129.88,130.15,130.82,130.88,131.44,131.66(2 \mathrm{C})$, 135.38 (2C), 135.44, 137.37, 141.81 (Ar-C), 147.54 $(C=N), 156.20(C=N), 169.20(C=S)$. Anal. Calcd. for $\mathrm{C}_{23} \mathrm{H}_{15} \mathrm{Cl}_{4} \mathrm{~N}_{5} \mathrm{~S}: \mathrm{C}, 51.61 ; \mathrm{H}, 2.82 ; \mathrm{N}, 13.08 \%$. Found: C, $51.56 ; \mathrm{H}, 2.77 ; \mathrm{N}, 13.03 \%$.

4-(4-Bromophenyl)-5-\{[5, 6-dichloro-2-(3,4dichlorobenzyl)-1 ${ }^{-1}$-benzimidazol-1-yl]methyl\}-4H1,2,4-triazole-3-thiol (6d). Yield: $3.93 \mathrm{~g}(64 \%) ; \mathrm{Mp}$ : $172-173^{\circ} \mathrm{C} ;{ }^{1} \mathrm{H}-\mathrm{NMR}\left(400 \mathrm{MHz}, \mathrm{DMSO}^{-\mathrm{d}_{6}}\right) \delta(\mathrm{ppm})$ : $4.25\left(\mathrm{~s}, 2 \mathrm{H}, \mathrm{CH}_{2}\right), 5.43\left(\mathrm{~s}, 2 \mathrm{H}, \mathrm{NCH}_{2}\right), 7.17-7.91(\mathrm{~m}$, 9H, Ar-H), $13.92\left(\mathrm{~s},{ }^{1} \mathrm{H}, \mathrm{SH}\right) ;{ }^{13} \mathrm{C}-\mathrm{NMR}(100 \mathrm{MHz}$, DMSO- $\left.\mathrm{d}_{6}\right): \delta 32.05\left(\mathrm{CH}_{2}\right), 45.53\left(\mathrm{NCH}_{2}\right), 112.67$, $119.47,123.69,124.90,125.23,129.97,130.02(2 \mathrm{C})$, $130.97,130.72,131.33,131.50,131.76,132.52(2 \mathrm{C})$, 135.86, 137.30, $141.69(\mathrm{Ar}-\mathrm{C}), 147.49(\mathrm{C}=\mathrm{N}), 156.03$ $(\mathrm{C}=\mathrm{N}), 169.13(\mathrm{C}=\mathrm{S})$. Anal. Calcd. for $\mathrm{C}_{23} \mathrm{H}_{14} \mathrm{BrCl}_{4} \mathrm{~N}_{5} \mathrm{~S}$ : C, 44.98; $\mathrm{H}, 2.30 ; \mathrm{N}, 11.40 \%$. Found: $\mathrm{C}, 44.92 ; \mathrm{H}$, $2.23 ; \mathrm{N}, 11.33 \%$.

\section{Synthesis of Compound 7a-d}

A mixture of corresponding thiosemicarbazides $(0.01 \mathrm{~mol})(6 \mathrm{a}-\mathrm{d})$ in cold concentrated sulfuric acid $(10 \mathrm{~mL})$ was stirred for $10 \mathrm{~min}$. and then left for another $30 \mathrm{~min}$. at room temperature. The resulting solution was poured slowly into ice-cold water, neutralized to $\mathrm{pH} 8$ with ammonia and the precipitated product was filtered, washed with water and recrystallized from ethanol.

5- $\{[5,6$-Dichloro-2-(3,4-dichlorobenzyl)${ }^{1} \mathrm{H}$-benzimidazol-1-yl]methyl\}-N-methyl-1,3,4thiadiazol-2-amine (7a). Yield:3.12 g (66\%); Mp: $240-241^{\circ} \mathrm{C} ;{ }^{1} \mathrm{H}-\mathrm{NMR}\left(400 \mathrm{MHz}\right.$, DMSO-d $\left.\mathrm{d}_{6}\right) \delta$ (ppm): $2.50\left(\mathrm{~s}^{3}{ }^{3} \mathrm{H}, \mathrm{CH}_{3}\right), 4.37\left(\mathrm{~s},{ }^{2} \mathrm{H}, \mathrm{CH}_{2}\right), 5.78$ $\left(\mathrm{s},{ }^{2} \mathrm{H}, \mathrm{NCH}_{2}\right), 7.26-7.88\left(\mathrm{~m},{ }^{5} \mathrm{H}, \mathrm{Ar}-\mathrm{H}\right), 7.99\left(\mathrm{~s},{ }^{1} \mathrm{H}\right.$, $\mathrm{NH}) ;{ }^{13} \mathrm{C}-\mathrm{NMR}\left(100 \mathrm{MHz}, \mathrm{DMSO}-\mathrm{d}_{6}\right): \delta 31.71\left(\mathrm{CH}_{3}\right)$, $32.18\left(\mathrm{CH}_{2}\right), 42.47\left(\mathrm{NCH}_{2}\right), 112.69,120.57,125.08$, 125.31, 129.94, 130.00, 131.39, 131.58, 131.68, 135.01, 137.59, 142.21 (Ar-C), $152.32(\mathrm{C}=\mathrm{N}), 156.72$
$(\mathrm{C}=\mathrm{N}), 170.81$ (C-S). Anal. Calcd. for $\mathrm{C}_{18} \mathrm{H}_{13} \mathrm{Cl}_{4} \mathrm{~N}_{5} \mathrm{~S}$ : C, 45.69; $\mathrm{H}, 2.77 ; \mathrm{N}, 14.80 \%$. Found: $\mathrm{C}, 45.62 ; \mathrm{H}$, $2.72 ; \mathrm{N}, 14.75 \%$.

5-\{[5,6-Dichloro-2-(3,4-dichlorobenzyl)${ }^{1} \mathrm{H}$-benzimidazol-1-yl]methyl\}-N-ethyl-1,3,4thiadiazol-2-amine (7b). Yield: $3.16 \mathrm{~g}$ (65\%); Mp: $192-193^{\circ} \mathrm{C} ;{ }^{1} \mathrm{H}-\mathrm{NMR}$ (400 MHz, DMSO-d 6 ) $\delta$ (ppm): $1.10\left(\mathrm{t}, J=6.8,3 \mathrm{H}, \mathrm{CH}_{3}\right), 3.18(\mathrm{q}, J=6.8,2 \mathrm{H}$, $\mathrm{CH} 2), 4.37\left(\mathrm{~s}, 2 \mathrm{H}, \mathrm{CH}_{2}\right), 5.77\left(\mathrm{~s}, 2 \mathrm{H}, \mathrm{NCH}_{2}\right), 7.26(\mathrm{~d}$, $\left.\mathrm{J}=8.0,{ }^{1} \mathrm{H}, \mathrm{Ar}-\mathrm{H}\right), 7.49-7.54(\mathrm{~m}, 2 \mathrm{H}, \mathrm{Ar}-\mathrm{H}), 7.73-7.83$ $(\mathrm{m}, 2 \mathrm{H}, \mathrm{Ar}-\mathrm{H}), 7.99\left(\mathrm{~s},{ }^{1} \mathrm{H}, \mathrm{NH}\right) ;{ }^{13} \mathrm{C}-\mathrm{NMR}(100 \mathrm{MHz}$, DMSO-d $\left.)_{6}\right): \delta 14.79\left(\mathrm{CH}_{3}\right), 32.18\left(\mathrm{CH}_{2}\right), 40.57\left(\mathrm{CH}_{2}\right)$, $42.45\left(\mathrm{NCH}_{2}\right), 112.69,120.54,125.11,125.35,129.95$, $130.13,130.93,131.40,131.65,135.02,137.54,142.18$ $(\operatorname{Ar}-\mathrm{C}), 152.13(\mathrm{C}=\mathrm{N}), 155.97(\mathrm{C}=\mathrm{N}), 169.88(\mathrm{C}-\mathrm{S})$. Anal. Calcd. for $\mathrm{C}_{19} \mathrm{H}_{15} \mathrm{Cl}_{4} \mathrm{~N}_{5} \mathrm{~S}: \mathrm{C}, 46.84 ; \mathrm{H}, 3.10 ; \mathrm{N}$, $14.37 \%$. Found: $C, 46.79 ; \mathrm{H}, 3.04 ; \mathrm{N}, 14.31 \%$.

5-\{[5,6-Dichloro-2-(3,4-dichlorobenzyl)${ }^{1} \mathrm{H}$-benzimidazol-1-yl]methyl\}-N-phenyl-1,3,4thiadiazol-2-amine (7c). Yield: 3.32g (62\%); Mp: 223-224 ${ }^{\circ} \mathrm{C} ;{ }^{1} \mathrm{H}-\mathrm{NMR}(400 \mathrm{MHz}$, DMSO-d 6 ) $\delta$ (ppm): $4.39\left(\mathrm{~s},{ }^{2} \mathrm{H}, \mathrm{CH}_{2}\right), 5.84\left(\mathrm{~s}, 2 \mathrm{H}, \mathrm{NCH}_{2}\right), 6.98(\mathrm{t}, \mathrm{J}=7.6$, $\left.{ }^{1} \mathrm{H}, \mathrm{Ar}-\mathrm{H}\right), 7.25-7.33\left(\mathrm{~m},{ }^{3} \mathrm{H}, \mathrm{Ar}-\mathrm{H}\right), 7.46-7.53\left(\mathrm{~m},{ }^{4} \mathrm{H}\right.$, Ar-H), 7.91 (s, $\left.{ }^{1} \mathrm{H}, \mathrm{Ar}-\mathrm{H}\right), 8.05\left(\mathrm{~s},{ }^{1} \mathrm{H}, \mathrm{Ar}-\mathrm{H}\right), 10.34$ $\left(\mathrm{br},{ }^{1} \mathrm{H}, \mathrm{NH}\right) ;{ }^{13} \mathrm{C}-\mathrm{NMR}\left(100 \mathrm{MHz}, \mathrm{DMSO}-\mathrm{d}_{6}\right): \delta 32.12$ $\left(\mathrm{CH}_{2}\right), 42.31\left(\mathrm{NCH}_{2}\right), 112.73,116.78,117.97(2 \mathrm{C})$, 120.59, 122.56, 125.14, 129.51, 129.99 (2C), 130.93, 131.38, 135.11, 137.34, 140.81, 142.21 (Ar-C), 154.30 $(C=N), 156.17(C=N), 165.18(C-S)$. Anal. Calcd. for $\mathrm{C}_{23} \mathrm{H}_{15} \mathrm{Cl}_{4} \mathrm{~N}_{5} \mathrm{~S}: \mathrm{C}, 51.61 ; \mathrm{H}, 2.82 ; \mathrm{N}, 13.08 \%$. Found: C, $51.55 ; \mathrm{H}, 2.75 ; \mathrm{N}, 13.03 \%$.

N-(4-Bromophenyl)-5-\{[5,6-dichloro-2-(3,4dichlorobenzyl)-1 $\mathrm{H}$-benzimidazol-1-yl]methyl\}1,3,4-thiadiazol-2-amine (7d). Yield:3.86 g (63\%); Mp: $256-257^{\circ} \mathrm{C} ;{ }^{1} \mathrm{H}-\mathrm{NMR}\left(400 \mathrm{MHz}\right.$, DMSO-d $\left.{ }_{6}\right) \delta$ (ppm): $4.38\left(\mathrm{~s},{ }^{2} \mathrm{H}, \mathrm{CH}_{2}\right), 5.89\left(\mathrm{~s}^{2}{ }^{2} \mathrm{H}, \mathrm{NCH}_{2}\right), 7.25-$ $8.03\left(\mathrm{~m},{ }^{11} \mathrm{H}, \mathrm{Ar}-\mathrm{H}\right), 10.21\left(\mathrm{br},{ }^{1} \mathrm{H}, \mathrm{NH}\right) ;{ }^{13} \mathrm{C}-\mathrm{NMR}$ $\left(100 \mathrm{MHz}, \mathrm{DMSO}-\mathrm{d}_{6}\right): \delta 32.12\left(\mathrm{CH}_{2}\right), 42.30\left(\mathrm{NCH}_{2}\right)$, $112.72,113.82,119.47,119.88,120.57,125.16,125.43$, $129.87,130.91,131.47,132.19,135.11,135.39,137.25$, 137.45, 138.30, 140.07, 142.17 (Ar-C), 154.87 $(C=N), 156.06(C=N), 165.24(C-S)$. Anal. Calcd. for $\mathrm{C}_{23} \mathrm{H}_{14} \mathrm{BrCl}_{4} \mathrm{~N}_{5} \mathrm{~S}$ : C, 44.98; $\mathrm{H}, 2.30 ; \mathrm{N}, 11.40 \%$. Found: $\mathrm{C}, 44.93 ; \mathrm{H}, 2.23 ; \mathrm{N}, 11.35 \%$. 


\section{Biological Method}

\section{Antioxidant Activity}

In this study, the antioxidant activities of the synthesized compounds were determined using Cupric reducing antioxidant capacity assay, radical scavenging activities of the synthesized compounds ABTS (2,2-azinobis(3ethylbenzothiazoline-6-sulfonic acid) and DPPH (1,1- diphenyl-2-picrylhydrazyl) systems. Catechin, BHT (butylated hydroxytoluene) and Trolox (Sigma Chemical Co, USA) were used as reference antioxidants.

\section{Cupric Reducing Antioxidant Capacity (CUPRAC) assay}

The cupric reducing antioxidant capacity of the synthesized compounds was determined according to the method of Apak et al. [45]. To a test tube $1 \mathrm{~mL}$ each of $10 \mathrm{mM} \mathrm{Cu}$ (II) chloride (Sigma Chemical Co, USA), 7.5 mM neocuprine (Sigma Chemical Co, USA), and $\mathrm{NH}_{4} \mathrm{Ac}$ (Fluka Chemical Co., Switzerland buffer (1 M, pH 7.0) solutions were added. About $20 \mu \mathrm{L}$ of compound solution in DMSO and $1.080 \mathrm{~mL}$ of water were added to the initial mixture so as to make the final volume 4.1 $\mathrm{mL}$. The tubes were stoppered, and after $30 \mathrm{~min}$ the absorbance at $450 \mathrm{~nm}$ was recorded against a reagent blank containing no compound. Trolox ${ }^{\circledR}$ (Sigma Chemical Co, USA) was also tested under the same conditions as a standard antioxidant compound. The standard curve was linear between $4 \mathrm{mg} / \mathrm{mL}$ and $0.0156 \mathrm{mg} / \mathrm{mL}$ trolox $\left(r^{2}=0.999\right)$. CUPRAC values were expressed as $\mathrm{mg}$ Trolox equivalent of $1 \mathrm{mg}$ synthesized compound.

\section{DPPH-Free Radical Scavenging Assay}

The 1,1-diphenyl-2-picrylhydrazyl (DPPH) radical has been used widely in the model system to investigate the scavenging activities of several synthesized and natural compounds [46]. The DPPH radical scavenging activity of the synthesized compounds was measured using the method of Brand-Williams [47]. Briefly, $0.1 \mathrm{mM}$ DPPH (2,2-diphenyl-1-picrylhydrazyl, AldrichGermany) was prepared in methanol. One milliliter of this solution was added $0.5 \mathrm{~mL}$ of the sythesized compound solution in DMSO. After, in the dark for 50 min incubation period at room temperature, the decrease in absorbance at $517 \mathrm{~nm}$ was measured, using a UV-Visible spectrophorometer (1601UV-Shimadzu, Australia). All determinations were carried out three times. Radical scavenging activity was measured by using trolox, BHT and catechin (Sigma Chemical Co, USA) as standards and all values are expressed as $\mathrm{SC}_{50}$ ( $\mu \mathrm{g}$ compound per $\mathrm{mL}$ ), the concentration of the samples that causes 50\% scavenging of DPPH radical. The DPPH radical stock solution was prepared fresh daily.

\section{ABTS•+ Radical Cation Decolorization Assay}

The ability of the synthesized compound to scavenge ABTS -+ radical was determined according to the literature [48]. ABTS [2,2'-azinobis(3-ethylbenzothiazoline-6-sulfonic acid)] was dissolved in water to a $7 \mathrm{mM}$ concentration. ABTS (Sigma Chemical Co, USA) radical cation $($ ABTS + )was produced by reacting ABTS stock solution with $2.45 \mathrm{mM}$ potassium persulfate (Sigma Chemical Co, USA), (final concentration) and allowing the mixture to stand in the dark for 16-18 $\mathrm{h}$ at room temperature. Before usage, the ABTS solution was diluted to get an absorbance of $0.700 \pm 0.020$ at $734 \mathrm{~nm}$ with PBS at $\mathrm{pH} 7.4$. The compound solution of $200 \mu \mathrm{L}$ was added to $1.8 \mathrm{~mL}$ of the resulting blue-green ABTS radical solution. After, incubation $5 \mathrm{~min}$ in the dark at room temperature, the decrease of absorbance at $734 \mathrm{~nm}$ was measured by using a UV-Visible spectrophorometer (1601UV-Shimadzu, Australia). All determinations were carried out three times. ABTS radical scavenging activity was measured by using trolox and catechin (Sigma Chemical Co, USA) as standards and the percentage scavenging was calculated from the formula

$\%$ Scavenging $=\left(O D_{\text {control }}-O D_{\text {test }}\right) /\left(O D_{\text {control }}\right) \times 100$

\section{In Vitro Anti-xanthine Oxidase Assay}

The inhibition of xanthine oxidase was measured by UV spectroscopy technique at $295 \mathrm{~nm}$ which attributes to released uric acid from xanthine. The inhibitory activity of each compound was determined using a slight modification of the reference methods [49]. Briefly, the reaction mixture consisted of $0.5 \mathrm{~mL}$ of the test compound, $0.77 \mathrm{~mL}$ of phosphate buffer $(\mathrm{pH} 7.8)$ and $0.07 \mathrm{~mL}$ of bovine milk xanthine oxidase (Sigma-Aldrich, St. Louis, USA), which was prepared immediately 
before use. After preincubation at $25^{\circ} \mathrm{C}$ for 15 minutes the reaction was initiated by the addition $0.66 \mathrm{~mL}$ of substrate solution into the mixture. The assay mixture was incubated at $25^{\circ} \mathrm{C}$ for 15 min. The reaction was stopped by adding $0.2 \mathrm{~mL}$ of $0.5 \mathrm{~N} \mathrm{HCl}$ and the absorbance was measured at $295 \mathrm{~nm}$ using UV/vis spectrophotometer (1601UV-Shimadzu, Australia). A well known XO inhibitor (XOI), allopurinol (Sigma-Aldrich, St. Louis, USA) was used as a positive control for the inhibition test. Residual activities werecalculated by comparing to control without inhibitor. The assay was done in triplicate. The $I C_{50}$ value was determined as the concentration of compound that give $50 \%$ inhibition of maximal activity.

\section{Urease Inhibition Assay}

Urease is an enzyme that catalyzes the hydrolysis of urea into carbon dioxide and ammonia. The production of ammonia was measured by indophenol method and used to determine the urease inhibitory activity [50]. Reaction mixtures including $200 \mu \mathrm{L}$ of Jack Bean Urease, $500 \mu \mathrm{L}$ of buffer $\left(100 \mathrm{mM}\right.$ urea, $0.01 \mathrm{M} \mathrm{K}_{2} \mathrm{HPO}_{4}$ $1 \mathrm{mM}$ EDTA and $0.01 \mathrm{M} \mathrm{LiCl}, \mathrm{pH}$ 8.2) and $100 \mu \mathrm{L}$ of the test compounds were incubated with at room temperature for $20 \mathrm{~min}$. The phenol reagent $(550 \mu \mathrm{L}, 1 \% \mathrm{w} / \mathrm{v}$ phenol and $0.005 \% \mathrm{w} / \mathrm{v}$ sodium nitroprusside) and alkali reagent $(650 \mu \mathrm{L}$, $0.5 \% \mathrm{w} / \mathrm{v}$ sodium hydroxide and $0.1 \% \mathrm{v} / \mathrm{v} \mathrm{NaOCl}$ ) were added to each tube and the increasing absorbance at $625 \mathrm{~nm}$ was measured after 50 min, using a UV/vis spectrophotometer (1601UVShimadzu, Australia). The percentage inhibition was calculated from the formula $\%$ Inhibition = $\left(O D_{\text {control }}-O D_{\text {test }}\right) /\left(O D_{\text {control }}\right) \times 100$ Thiourea was used as the standard inhibitor. In order to calculate $\mathrm{IC}_{50}$ values, different concentrations of synthesized compounds and standard were assayed at the same reaction conditions.

\section{RESULT AND DISCUSSION}

\section{Chemistry}

5,6-Dichloro-2-(3,4-dichlorobenzyl) ${ }^{-1} \mathrm{H}$ benzimidazole (2) was prepared according to our previously reported procedure [51]. This compound was treated with methyl bromoacetate in the presence of dry potassium carbonate to prepare methyl [5, 6-dichloro2-(3,4-dichlorobenzyl) ${ }^{-1} \mathrm{H}$-benzimidazol-1-yl] acetate (3).The compound 3 was refluxed with hydrazine monohydrate in ethanol to synthesize 2-[5, 6-dichloro-2-(3, 4-dichlorobenzyl)-1 ${ }^{-1}$ benzimidazol-1-yl]acetohydrazide (4). Then, the compound 4 was treated with corresponding isothiocyanate derivatives to synthesize corresponding carbothioamide derivatives (5ad). The compounds $5 \mathrm{a}$-d are well-known for cyclization reaction [42,51-53] Treatment of compounds $5 \mathrm{a}-\mathrm{d}$ with aquous $\mathrm{NaOH}$ resulted in the cyclization leading to the formation 1,2,4-triazole-3-thiol derivatives (6a-d). The acidic treatment of compound $5 \mathrm{a}-\mathrm{d}$ in cold conditions and then at room temperature resulted in the formation of 1,3,4-thiadiazol-2-amine derivatives 7a-d (Scheme 1).

Spectral investigation of newly synthesized compounds is accordance with proposed structures. $\mathrm{NCH}_{2}$ and $\mathrm{OCH}_{3}$ signals in ${ }^{1} \mathrm{H}-\mathrm{NMR}$ and ${ }^{13} \mathrm{C}$-NMR spectra of compound 3 showed the alkylation reaction. The leaving of $\mathrm{OCH}_{3}$ signal and the formation of new $\mathrm{NH}$ and $\mathrm{NH}_{2}$ in ${ }^{1} \mathrm{H}-\mathrm{NMR}$ spectra of compound 4 proved the hydrazide formation. In ${ }^{1} \mathrm{H}-\mathrm{NMR}$ spectra of compounds 5a-d, leaving of $\mathrm{NH}_{2}$ signal and formation of two new $\mathrm{NH}$ signals and new alkyl or aryl group coming from isothiocyanate derivatives showed carbothioamide derivatives. Also, $\mathrm{C}=\mathrm{S}$ signals were shown at $166.60-170.40 \mathrm{ppm}$ in ${ }^{13} \mathrm{C}$-NMR spectra of compounds $5 \mathrm{a}-\mathrm{d}$. In ${ }^{1} \mathrm{H}-\mathrm{NMR}$ spectra of compounds $6 \mathrm{a}-\mathrm{d}, \mathrm{SH}$ signal was presented at about $13 \mathrm{ppm}$. This signal was not shown in some of the compounds because of exchanging with deuterium of NMR solvent. In ${ }^{13} \mathrm{C}$-NMR spectra of these compounds, $\mathrm{C}=\mathrm{S}$ signal was shown between 167.57-169.20 ppm. In these spectra, $\mathrm{C}=\mathrm{N}$ signal coming from triazole ring was shown at about $147 \mathrm{ppm}$. In ${ }^{1} \mathrm{H}-\mathrm{NMR}$ spectra of compounds $7 \mathrm{a}$ d, NH signal was shown between 7.99-10.21 ppm and in ${ }^{13} \mathrm{C}$-NMR spectra, C-S signal was shown between 165.18-170.81 ppm. Also, all compounds showed suitable molecular ion peaks and correct elemental analysis results. 


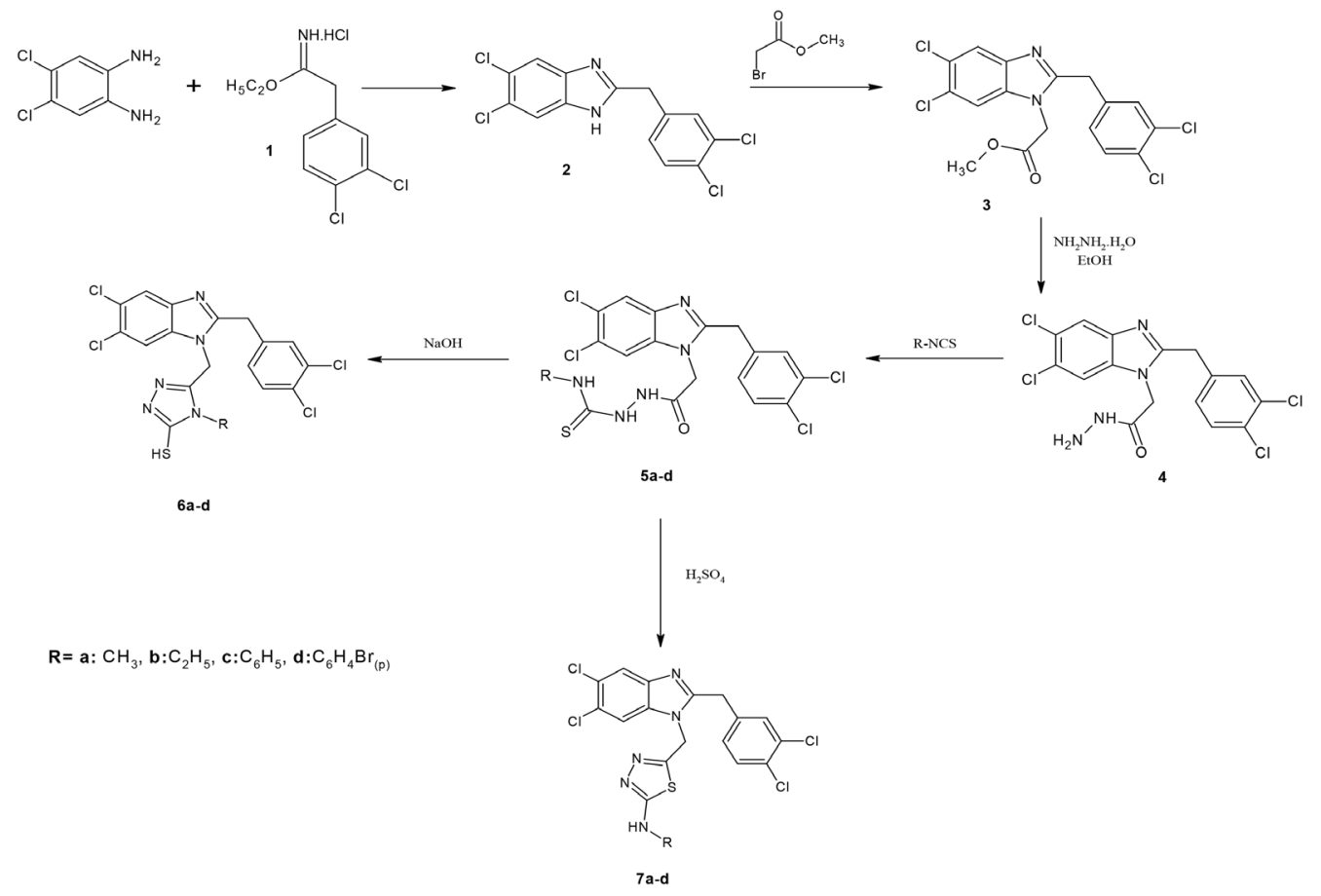

Scheme 1. Synthetic route for target compounds.

\section{Biological Activity}

\section{CUPRAC Antioxidant Activity Assay}

The CUPRAC method of antioxidant capacity measurement, introduced by the analytical chemistry laboratory of Istanbul University to world literature [45], is based on the absorbance measurement of the CUPRAC chromophore, $\mathrm{Cu}(\mathrm{I})$-neocuproine $(\mathrm{Nc})$ chelate, formed as a result of the redox reaction of antioxidants with the CUPRAC reagent, bis(neocuproine)copper(II) cation [Cu(II)-Nc], where absorbance is recorded at the maximal light absorption wavelength of $450 \mathrm{~nm}$. The orange-yellow colour is due to the $\mathrm{Cu}(\mathrm{I})-\mathrm{Nc}$ charge-transfer complex formed [49]. The antioxidant effects were classified by two groups; compound 4, the most effective, was the first. The others, evaluated by the range of highly to moderately, were the second (Table 1).

\section{DPPH Scavenging Assay}

The DPPH method is based on the fact that the free radical is purple in color, and that the purple color of DPPH decays in the presence of an antioxidant. The color changed from purple to yellow after reduction, which can be quantified by its decrease of absorbance at wavelength 517 $\mathrm{nm}$. The results were expressed as $\mathrm{SC}_{50}(\mu \mathrm{g} / \mathrm{mL})$, which was calculated from the curves by plotting absorbance values, the $\mathrm{SC}_{50}$ values representing the concentration of the compound $(\mu \mathrm{g} / \mathrm{mL})$ required to inhibit $50 \%$ of the radicals. Because of having the lowest $\mathrm{SC}_{50}$ value, compound 4 was the best compared to the other synthesized compounds. Also, compound 6b, 5a, 5b, 5c, and $5 d$ showed good DPPH radical scavenging activity. Besides these efficient results, some of them, which were compounds $6 \mathrm{~d}, 7 \mathrm{~b}, 7 \mathrm{c}$, and $7 \mathrm{~d}$, showed weakly activity (Table 1 ).

\section{ABTS Scavenging Assay}

The pre-formed radical monocation of 2,2 -azinobis-(3-ethylbenzothiazoline-6-sulfonic acid) (ABTS $\cdot+$ ) is generated by oxidation of ABTS with potassium persulfate and is reduced in the presence of such hydrogen-donating antioxidants. The influences of both the concentration of antioxidant and duration of reaction on the inhibition of the radical cation absorption are taken into account when determining the antioxidant activity [47]. Compound 4 showed more scavenging activity than bht standart (Table 1, Figure 1). According to the having effective activity by decreasing degree, it could 
Table 1. Antioxidant activity values to CUPRAC method, SC50 values to DPPH and ABTS method of synthesized compounds.

\begin{tabular}{|c|c|c|c|}
\hline & CUPRAC method & ABTS method & DPPH method \\
\hline Compound no. & (mg TEAC/mg compound) & $\mathrm{SC}_{50}(\mu \mathrm{g} / \mathrm{mL})$ & $\mathrm{SC}_{50}(\mu \mathrm{g} / \mathrm{mL})$ \\
\hline 2 & $0.233 \pm 0.009$ & $44.61 \pm 0.07$ & $106.54 \pm 0.16$ \\
\hline 3 & $0.326 \pm 0.018$ & $42.34 \pm 0.22$ & $100.87 \pm 0.43$ \\
\hline 4 & $1.716 \pm 0.021$ & $9.51 \pm 0.08$ & $25.55 \pm 0.29$ \\
\hline $5 a$ & $1.115 \pm 0.015$ & $17.12 \pm 0.06$ & $38.80 \pm 0.22$ \\
\hline $5 b$ & $0.785 \pm 0.003$ & $17.46 \pm 0.11$ & $36.80 \pm 0.09$ \\
\hline $5 c$ & $1.040 \pm 0.019$ & $17.39 \pm 0.24$ & $37.49 \pm 0.11$ \\
\hline $5 d$ & $0.946 \pm 0.007$ & $17.79 \pm 0.17$ & $39.48 \pm 0.23$ \\
\hline $6 a$ & $0.801 \pm 0.009$ & $25.10 \pm 0.18$ & $82.97 \pm 0.19$ \\
\hline $6 \mathrm{~b}$ & $1.306 \pm 0.016$ & $13.62 \pm 0.19$ & $27.06 \pm 0.21$ \\
\hline $6 c$ & $0.441 \pm 0.011$ & $69.94 \pm 0.41$ & $98.32 \pm 0.59$ \\
\hline $6 d$ & $0.502 \pm 0.006$ & $35.19 \pm 0.29$ & $82.99 \pm 0.25$ \\
\hline $7 a$ & $0.306 \pm 0.007$ & $70.43 \pm 0.19$ & $121.54 \pm 1.10$ \\
\hline $7 b$ & $0.180 \pm 0.006$ & $94.24 \pm 0.46$ & $224.85 \pm 0.98$ \\
\hline $7 c$ & $0.263 \pm 0.019$ & $89.12 \pm 0.98$ & $168.45 \pm 0.72$ \\
\hline $7 d$ & $0.179 \pm 0.008$ & $112.48 \pm 0.57$ & $174.28 \pm 0.68$ \\
\hline BHT & - & $12.83 \pm 0.06$ & $13.97 \pm 0.13$ \\
\hline Trolox ${ }^{\circledR}$ & - & $6.11 \pm 0.04$ & $6.73 \pm 0.05$ \\
\hline Catechin & - & $4.19 \pm 0.04$ & $4.79 \pm 0.03$ \\
\hline
\end{tabular}

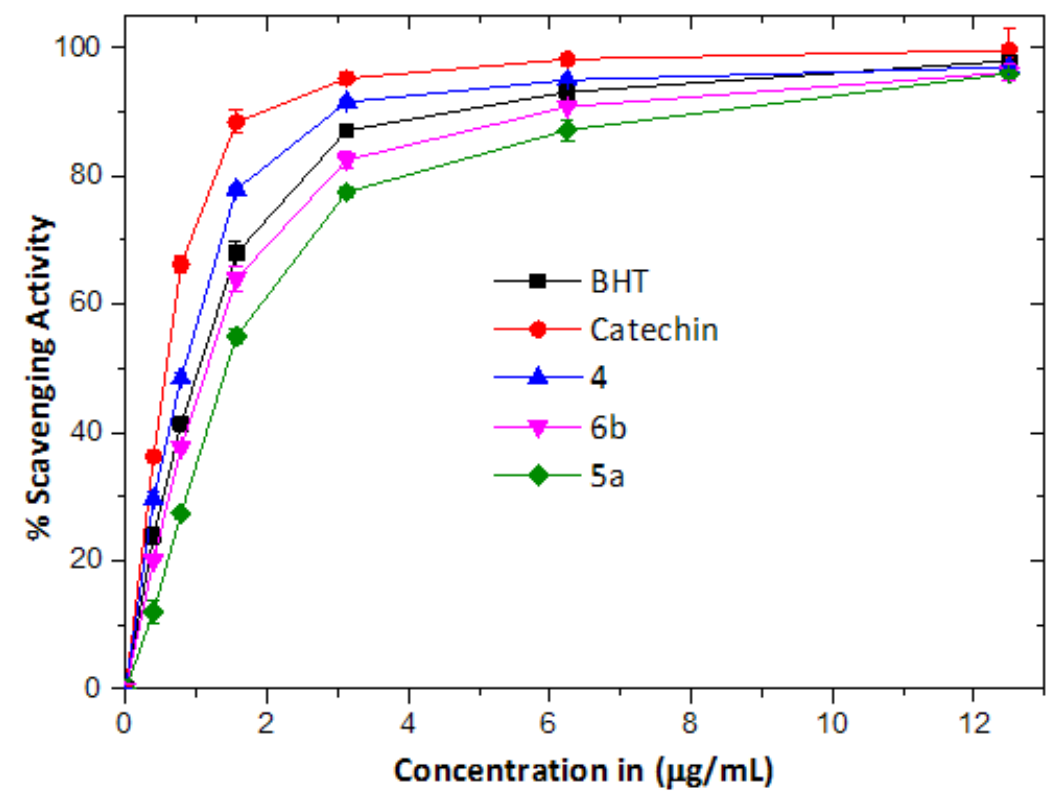

Figure 1. Evaluation radical scavenging properties of some compounds and standards by ABTS ++ method. Scavenging activities of compounds are expressed as the mean \pm SD in triplicate. 
Table 2. Results of \% residual XO activity and $I C_{50}$ values of the synthesized chemical compounds.

\begin{tabular}{ccc}
\hline & Residual Xo activity (\%) & \\
\hline Compound & $(125 \mu \mathrm{g} / \mathrm{mL})$ & $\mathrm{IC}_{50}(\mu \mathrm{M})$ \\
\hline Control & 100.00 & - \\
\hline $\mathbf{4}$ & $9.81 \pm 0.41$ & $61.03 \pm 0.38$ \\
\hline $\mathbf{5 a}$ & $10.56 \pm 0.52$ & $61.34 \pm 0.63$ \\
\hline $\mathbf{5 b}$ & $10.31 \pm 0.24$ & $63.58 \pm 0.31$ \\
\hline $\mathbf{5 c}$ & $2.56 \pm 0.17$ & $47.90 \pm 0.25$ \\
\hline $\mathbf{5 d}$ & $0.56 \pm 0.22$ & $40.34 \pm 0.33$ \\
\hline $\mathbf{6 a}$ & $23.19 \pm 0.72$ & $99.36 \pm 0.97$ \\
\hline $\mathbf{6 b}$ & $9.06 \pm 0.06$ & $53.38 \pm 0.09$ \\
\hline $\mathbf{6 c}$ & $6.81 \pm 0.09$ & $41.30 \pm 0.11$ \\
\hline $\mathbf{6 d}$ & $0.44 \pm 0.35$ & $33.87 \pm 0.46$
\end{tabular}

be numbered as compounds $5 a, 5 b, 5 c, 5 d, 6 b, 6 d$, 2 and 3 , respectively (Table 1 ).

\section{Anti-xanthine Oxidase Activity}

All the synthesized compounds were evaluated with regard for bovine milk xanthine oxidase activity. The results had shown that a compound $6 \mathrm{~d}$ had promising activity to inhibit $\mathrm{XO}$ up to $99.56 \%$ at concentration of $125 \mathrm{mg} / \mathrm{mL}$ (Table 2 ). Among the synthesized compounds, $6 \mathrm{~d}$ displayed the best inhibitory effect against $\mathrm{XO}$ with an $I_{50}$ value of $33.87 \pm 0.46 \mu \mathrm{M}$. Compounds $5 \mathrm{c}, 5 \mathrm{~d}$ and $6 \mathrm{c}$ showed moderate $\mathrm{XO}$ enzyme inhibition activity.

$I C_{50}$ values of Allopurinol and compound $6 \mathrm{~d}$ were calculated as $33.87 \pm 0.46 \mathrm{mM}$ and $4.09 \pm 0.17$ $\mathrm{mM}$, respectively. The synthesized compound $6 d$ can be evaluated as a good and $5 c, 5 d$ and $6 \mathrm{c}$ moderate. According to results, especially these compounds could be seen an alternative to Allopurinol.

\section{Anti-urease Activity}

The synthesized compounds were assayed for their in vitro inhibitory activity against Jack Bean urease. $I_{50}$ value of thiourea with $11.91 \pm 0.33$ $\mu \mathrm{M}$ was used as standard inhibitor. Initially, all synthesized compounds were screened $50 \mu \mathrm{g} / \mathrm{mL}$ at final concentration. Among the synthesized compounds, $5 \mathrm{~b}$ exhibited the best inhibitory effect against urease. The compound $5 \mathrm{~b}$ inhibited urease activity by $66.44 \%, 78.67 \%$ and $87.33 \%$ at concentrations of $12.5,25$ and $50 \mu \mathrm{g} / \mathrm{mL}$, respectively. $I C_{50}$ values of Thiourea, compounds $5 \mathrm{~b}$ and $5 \mathrm{c}$ were determined as $11.91 \pm 0.33,7.41 \pm 0.13$ and $10.48 \pm 0.15 \mu \mathrm{g} / \mathrm{mL}$, respectively.

Until now, only one compound, acetohydroxamic acid, has been clinically used for the treatment of urinary tract infections by urease inhibition. Unfortunately, it exhibits severe side effects. Thus, it seems that the full potential of urease inhibition has not yet been fully explored.

Compounds $5 a$ and $5 b$, are more effective inhibitor than thiourea, can be considered as potential antibiotics to treat infections. The other compounds have moderate or little inhibitory activity (Table 3). Dose-dependent inhibitory effect of compounds $5 a-c$ and $6 b$ were pictured in Figure 2.

\section{CONCLUSION}

In conclusion, we have synthesized some chlorine containing benzimidazoles and investigated their antioxidant, xanthine oxidase and urease Inhibitory activities. Due to risk of clinically 
Table 3. Inhibitory activities and IC $C_{50}$ values of the synthesized compounds against Jack Bean urease.

\begin{tabular}{ccc}
\hline & \% Inhibition & \\
\hline Compound No & $(50 \mu \mathrm{g} / \mathrm{mL})$ & $\mathrm{IC}_{50}(\mu \mathrm{g} / \mathrm{mL})$ \\
\hline 5a & $78.89 \%$ & $18.51 \pm 0.39$ \\
\hline 5b & $87.33 \%$ & $7.41 \pm 0.13$ \\
\hline 5c & $86.33 \%$ & $10.48 \pm 0.15$ \\
\hline 6a & $52.56 \%$ & $46.79 \pm 0.28$ \\
\hline 6b & $82.67 \%$ & $14.37 \pm 0.07$ \\
\hline 6c & $53.22 \%$ & $45.31 \pm 0.47$ \\
\hline Thiourea & $85.67 \%$ & $11.91 \pm 0.33$ \\
\hline
\end{tabular}

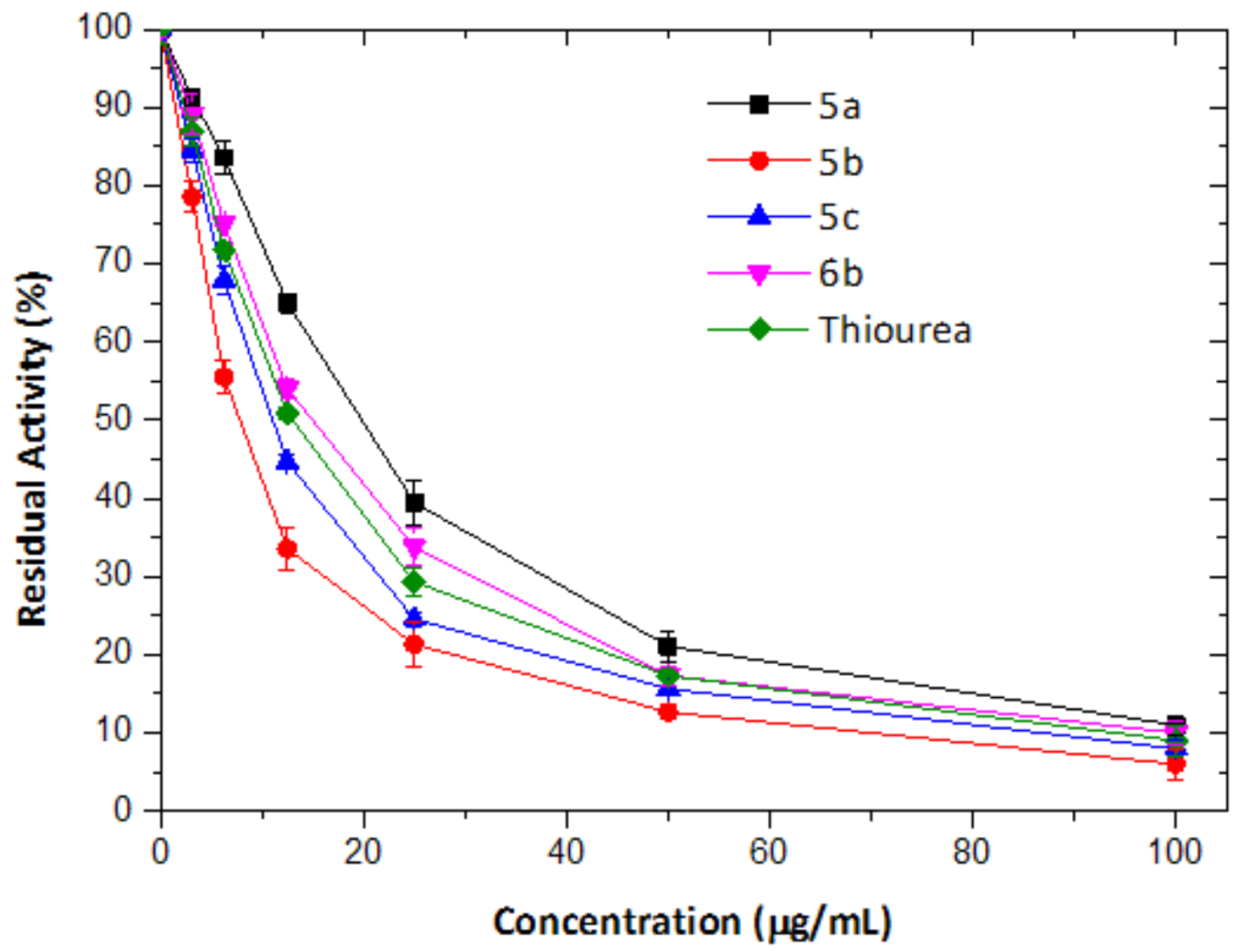

Figure 2. Dose-dependent inhibitory effect of some compounds and thiourea. Thiourea was used as standard inhibitor. Inhibitory effect of compounds and Thiourea were measured at the range of 100 to $6.25 \mu \mathrm{g} / \mathrm{mL}$ concentrations. Residual activities of compounds are expressed as the mean \pm SD in triplicate.

adverse effects encountered with the use of urease and xanthine oxidase inhibitor drugs, there is a need to investigate the new inhibitors with good bioavailability and low toxicity. The results of this study revealed that chlorine containing benzimidazole derivatives can be used inspiration for further investigation of as anti-XO, anti-urease and antioxidant molecules. 


\section{ACKNOWLEDGEMENT}

This work was supported by Recep Tayyip Erdogan University Scientific Research Project Unit (BAP) under project number: 2014.102.02.02. Authors thanks to Recep Tayyip Erdogan University for this support.

\section{References}

1. M. Li, W.J. Ding, B. Baruah, D.C. Crans, R.L. Wang Inhibition of protein tyrosine phosphatase $1 \mathrm{~B}$ and alkaline phosphatase by bis(maltolato)oxovanadium (IV), J Inorg Biochem, 102 (2008) 1846-1853.

2. P.A. Karplus, M.A. Pearson, R.P. Hausinger, 70 years of crystalline urease: What have we learned? Accounts Chem Res, 30 (1997) 330-337.

3. H.L.T. Mobley, M.D. Island, R.P. Hausinger, Molecularbiology of microbial ureases, Microbiol Rev, 59 (1995) 451-480.

4. X. Li, H.L.T. Mobley, Vaccines for Proteus mirabilish in urinary tract infection, Int J Antimicrob Ag, 19 (2002) 461-465.

5. Z.P. Xiao, T.W. Ma, W.C. Fu, X.C. Peng, A.H. Zhang, H.L. Zhu, The synthesis, structure and activity evaluation of pyrogallol and catechol derivatives as Helicobacter pylori urease inhibitors, Eur J Med Chem, 45 (2010) 5064-5070.

6. Z. Amtul, Atta-ur-Rahman, R.A. Siddiqui, M.I. Choudhary, Chemistry and mechanism of urease inhibition, Curr Med Chem, 9 (2002) 1323-1348.

7. M. Kot, W. Karcz, W. Zaborska, 5-Hydroxy-1,4naphthoquinone (juglone) and 2-hydroxy-1,4naphthoquinone (lawsone) influence on jack bean urease activity: Elucidation of the difference in inhibition activity, Bioorg Chem, 38 (2010) 132-137.

8. O. Bekircan, T. Ozen, N. Gumrukcuoglu, H. Bektas, Synthesis and antioxidant properties of some new 3-(4-chlorophenyl)-5-(pyridin-4-yl)-4H-1,2,4-triazole derivatives, Z Naturforsch B, 63 (2008) 548-554

9. M. Saleem, M. Rafiq, M. Hanif, N.H. Rama, S.Y. Seo, K.H. Lee, Synthesis, urease and acetylcholine esterase inhibition activities of some 1,4-disubstituted thiosemicarbazides and their 2,5-disubstituted thiadiazoles, B Korean Chem Soc, 33 (2012) 2741-2747.

10. S. Basoglu, A. Demirbas, S. Ulker, S. Alpay-Karaoglu, N. Demirbas, Design, synthesis and biological activities of some 7-aminocephalosporanic acid derivatives, Eur J Med Chem, 69 (2013) 622-631.

11. S. Uesato, Y. Hashimoto, M. Nishino, Y. Nagaoka, H. Kuwajima, N-substituted hydroxyureas as urease inhibitors, Chem Pharm Bull, 50 (2002) 1280-1282.

12. W.S. Faraci, B.W.V. Yang, D. Orourke, R.W. Spencer, Inhibition of helicobacter-pylori urease by phenyl phosphorodiamidates-mechanism of action, Bioorgan Med Chem, 3 (1995) 605-610.

13. J.B. Park, L. Imamura, K. Kobashi, Kinetic studies of Helicobacter pylori urease inhibition by a novel proton pump inhibitor, rabeprzole, Biol Pharm Bull, 19 (1996) 182-187.

14. H. Nagata, H. Satoh, T. Iwahi, T. Shimoyama, T. Tamura, Potent inhibitory action of the gastric proton pumb inhibitor lansoprazole against urease activity of Helicobacter pylori:unique action selective for $\mathrm{H}$. pylori cells, Antimicrob Agents Ch, 37 (1993) 769-774.
15. T.C. Kuhler, J. Fryklund, N.A. Bergman, J. Weilitz, A. Lee, H. Larsson, Structure-activity relationship of omeprazole and analogs as helicobacter-pylori urease inhibitors, J Med Chem, 38 (1995) 4906-4916.

16. L.G. Bundy, J.M. Bremner, Effects of substitued p-benzoquinones on urease activity in soils, Soil Biol Biochem, 5 (1973) 847-853.

17. M.J. Todd, R.P. Hausinger, Competitive inhibitors of klebsiella-aerogenes urease-mechanisms of interaction with the nickel active-site, J Biol Chem, 264 (1989) 15835-15842.

18. S.A. Sanders, V. Massey, The Thermodynamics of xanthine oxidoreductase catalysis, Antioxid Redox Sign, 1 (1999) 371-379.

19. A.K. Tausche, K. Richter, A. Grassler, S. Hansel, B. Roch, H.E. Schroder, Severe gouty arthritis refractory to anti-inflammatory drugs: treatment with antitumour necrosis factor alpha as a new therapeutic option, Ann Rheum Dis, 63 (2004) 1351-1352.

20. M. Fields, C.G. Lewis, M.D. Lure, Allopurinol, an inhibitor of xanthine oxidase, reduces uric acid levels and modifies the signs associated with copper deficiency in rats fed fructose, Free Radical Bio Med, 20 (1996) 595-600.

21. L.D. Kong, Y. Cai, W.W. Huang, C.H.K. Cheng, R.X. Tan, Inhibition of xanthine oxidase by some Chinese medicinal plants used to treat gout, J Ethnopharmacol, 73 (2000) 199-207.

22. A. Umpierrez, J. Cuesta-Herranz, M.D. Heras, M. Lluch-Bernal, E. Figueredo, J. Sastre, Successful desensitization of a fixed drug eruption caused by allopurinol, J Allergy Clin Immun, 101 (1998) 286-287.

23. C.E. Berry, J.M. Hare, Xanthine oxicloreductase and cardiovascular disease: molecular mechanisms and pathophysiological implications, J Physiol-London, 555 (2004) 589-606.

24. S.L. Wallach, The side effects of allopurinol, Hosp Pract, 33 (1998) 22-22.

25. A.P. Sweeney, S.G. Wyllie, R.A. Shalliker, J.L. Markham, Xanthine oxidase inhibitory activity of selected Australian native plants, J Ethnopharmacol, 75 (2001) 273-277.

26. R.J. Nijveldt, E. van Nood, D.E.C. van Hoorn, P.G. Boelens, K. van Norren, P.A.M. van Leeuwen, Flavonoids: a review of probable mechanisms of action and potential applications, Am J Clin Nutr, 74 (2001) 418-425.,

27. M. Ozyurek, B. Bektasoglu, K. Guclu, R. Apak, Measurement of xanthine oxidase inhibition activity of phenolics and flavonoids with a modified cupric reducing antioxidant capacity (CUPRAC) method, Anal Chim Acta, 636 (2009) 42-50.

28. A. Mobinikhaledi, N. Foroughifar, M. Kalhor, M. Mirabolfathy, Synthesis and antifungal activity of novel 2-benzimidazolylimino-5-arylidene-4thiazolidinones, J Heterocyclic Chem, 47 (2010) 7780.

29. J.J. Li, Heterocyclic Chemistry in Drug design, John Wiley and Sons, Hoboken, 2013.

30. J. Velik, V. Baliharova, J. Fink-Gremmels, S. Bull, J. Lamka, L. Skalova, Benzimidazole drugs and modulation of biotransformation enzymes, Res Vet Sci, 76 (2004) 95-108. 
31. P. Kohler, The biochemical basis of anthelmintic action and resistance, Int J Parasitol, 31 (2001) 336345.

32. M.M. Ramla, M.A. Omar, A.M.M. El-Khamry, H.I. El-Diwani, Synthesis and antitumor activity of 1-substituted-2-methyl-5-nitrobenzimidazoles, Bioorgan Med Chem, 14 (2006) 7324-7332.

33. R. Wubulikasimu, Y.B. Yang, F. Xue, X.J. Luo, D.P. Shao, Y.H. Li, R.M. Gao, W.D. Ye, Synthesis and biological evaluation of novel benzimidazole derivatives bearing a heterocyclic ring at $4 / 5$ position, B Korean Chem Soc, 34 (2013) 2297-2304.

34. G.R. Jadhav, M.U. Shaikh, R.P. Kale, M.R. Shiradkar, C.H. Gill, SAR study of clubbed $[1,2,4]$-triazolyl with fluorobenzimidazoles as antimicrobial and antituberculosis agents, Eur J Med Chem, 44 (2009) 2930-2935.

35. A. Husain, M. Rashid, M. Shaharyar, A.A. Siddiqui, R. Mishra, Benzimidazole clubbed with triazolothiadiazoles and triazolo-thiadiazines: New anticancer agents, Eur J Med Chem, 62 (2013) 785-798.

36. A. Husain, M. Rashid, R. Mishra, S. Parveen, D.S. Shin D. Kumar, Benzimidazole bearing oxadiazole and triazolo-thiadiazoles nucleus: Design and synthesis as anticancer agents, Bioorg Med Chem Lett, 22 (2012) 5438-5444.

37. D. Ramsbeck, M. Buchholz, B. Koch, L. Bohme, T. Hoffmann, H.U. Demuth, U. Heiser, Structure-activity relationships of benzimidazole-based glutaminyl cyclase inhibitors featuring a heteroaryl scaffold, J Med Chem, 56 (2013) 6613-6625.

38. V. Kovalishyn, J. Aires-de-Sousa, C. Ventura, R.E. Leitao, F. Martins, QSAR modeling of antitubercular activity of diverse organic compounds, Chemometr Intell Lab, 107 (2011) 69-74.

39. A. Khalafi-Nezhad, M.N.S. Rad, H. Mohabatkar, Z. Asrari, B. Hemmateenejad, Design, synthesis, antibacterial and QSAR studies of benzimidazole and imidazole chloroaryloxyalkyl derivatives, Bioorgan Med Chem, 13 (2005) 1931-1938.

40. Y.L. Gong, S.S. Karakaya, X.Y. Guo, P.R. Zheng, B. Gold, Y. Ma, D. Little, J. Roberts, T. Warder, X.J. Jiang, M. Pingle, C.F. Nathan, G. Liu, Benzimidazole-based compounds kill Mycobacterium tuberculosis, Eur J Med Chem, 75 (2014) 336-353.

41. Y.K. Yoon, M.A. Ali, A.C. Wei, A.N. Shirazi, K. Parang, T.S. Choon, Benzimidazoles as new scaffold of sirtuin inhibitors: Green synthesis, in vitro studies, molecular docking analysis and evaluation of their anti-cancer properties, Eur J Med Chem, 83 (2014) 448-454.

42. E. Mentese, N. Karaali, F. Yilmaz, S. Ulker, B. Kahveci, Microwave-assisted synthesis and biological evaluation of some benzimidazole derivatives containing a 1,2,4-triazol ring, Arch Pharm, 346 (2013) 556-561.
43. C. Kus, G. Ayhan-Kilcigil, S. Ozbey, F.B. Kaynak, M. Kaya, T. Coban, B. Can-Eke, Synthesis and antioxidant properties of novel N-methyl-1,3,4-thiadiazol-2amine and 4-methyl-2H-1,2,4-triazole-3(4H)-thione derivatives of benzimidazole class, Bioorgan Med Chem, 16 (2008) 4294-4303.

44. E. Mentese, S. Ulker, B. Kahveci, Synthesis and study of alpha-glucosidase inhibitory, antimicrobial and antioxidant activities of some benzimidazole derivatives containing triazole, thiadiazole, oxadiazole, and morpholine rings, Chem Heterocycl Comp, 50 (2015) 1671-1682.

45. R. Apak, S. Gorinstein, V. Bohm, K.M. Schaich, M. Ozyurek, K. Guclu, Methods of measurement and evaluation of natural antioxidant capacity/activity (IUPAC Technical Report), Pure Appl Chem, 85 (2013) 957-998.

46. Z. Can, B. Dincer, H. Sahin, N. Baltas, O. Yildiz, S. Kolayli, Polyphenol oxidase activity and antioxidant properties of Yomra apple (Malus communis L.) from Turkey, J Enzym Inhib Med Ch, 29 (2014) 829-835.

47. W. Brandwilliams, M.E. Cuvelier, C. Berset, Use of a Free-Radical Method to Evaluate Antioxidant Activity, Food Sci Technol-Leb, 28 (1995) 25-30.

48. R. Re, N. Pellegrini, A. Proteggente, A. Pannala, M. Yang, C. Rice-Evans, Antioxidant activity applying an improved ABTS radical cation decolorization assay, Free Radical Bio Med, 26 (1999) 1231-1237.

49. T. Hayashi, K. Sawa, M. Kawasaki, M. Arisawa, M. Shimizu, N. Morita, Inhibition of cows milk xanthineoxidase by flavonoids, J Nat Prod, 51 (1988) 345-348.

50. M.W. Weatherburn, Phenol-hypochlorite reaction for determination of ammonia, Anal Chem, 39 (1967) 971974.

51. E. Mentese, F. Yilmaz, N. Karaali, S. Ulker, B. Kahveci, Rapid synthesis and lipase inhibition activity of some new benzimidazole and perimidine derivatives, Russ J Bioorg Chem+, 40 (2014) 336-342.

52. E. Mentese, F. Yılmaz, F.B. Beris, B. Bekircan, B. Kahveci, Microwave-assisted synthesis of some new benzimidazole derivatives with their antimicrobial activity, Current Microwave Chemistry, 2 (2015) 3239.

53. E. Mentese, F. Yılmaz, N. Baltas, B. Bekircan, B. Kahveci, Synthesis and antioxidant activities of some new triheterocyclic compounds containing benzimidazole, thiophene, and 1,2,4-triazole rings, J Enzym Inhib Med Ch, 8 (2014) 1-7. 
